\title{
Two novel $A D A R 1$ gene mutations in two patients with dyschromatosis symmetrical hereditaria from birth
}

\author{
QIAN ZHOU* , LINGLIN ZHANG* , YUNFENG ZHANG, HAO LUO, \\ LUDE ZHU, PEIRU WANG, GUOLONG ZHANG and XIULI WANG \\ Institute of Photomedicine, Shanghai Skin Disease Hospital, \\ Tongji University School of Medicine, Shanghai 200443, P.R. China
}

Received January 21, 2016; Accepted February 9, 2017

DOI: $10.3892 / \mathrm{mmr} .2017 .6427$

\begin{abstract}
Dyschromatosis symmetrica hereditaria (DSH) is a rare type of pigmentary genodermatosis, which is autosomal dominantly inherited with high penetrance. The onset of DSH is typically during infancy or childhood. Cases of patients born with skin lesions have rarely been reported. Additionally, there have been few significant non-cutaneous complications reported with DSH. The present study reported two sporadic cases of patients born with DSH, confirmed by the identification of ADARl mutations. Additionally, comorbidity of DSH, congenital heart disease (CHD) and hemangioma disease were first reported. In the patient with isolated DSH from birth, a nonsense mutation (p.Y1192X) was identified, whereas in the second patient with DSH, CHD and hemangioma from birth, a frameshift mutation (p.Glu673ValfsX652) in ADARl was identified. To the best of the authors' knowledge, $>120$ mutations in $A D A R l$ have been reported to cause DSH; however, no previous studies have reported mutations in $A D A R 1$ in $\mathrm{DSH}$ at birth, with CHD and hemangioma. The novel variants described in the current study add to the current knowledge of ADARl mutations in DSH.
\end{abstract}

\section{Introduction}

Dyschromatosis symmetrica hereditaria (DSH; OMIM no. 127400 ) is a rare type of autosomal dominant genodermatosis that is characterized by hyper- and hypo-pigmented

Correspondence to: Dr Xiuli Wang or Dr Guolong Zhang, Institute of Photomedicine, Shanghai Skin Disease Hospital, Tongji University School of Medicine, 1278 Baode Road, Shanghai 200443, P.R. China

E-mail: wangxiuli20150315@163.com

E-mail: zglamu@163.com

*Contributed equally

Key words: dyschromatosis symmetrica hereditaria, mutation, ADARl, congenital heart disease macules on the dorsal aspects of the extremities (1). The causative gene for DSH was identified as adenosine deaminase acting on RNA 1 ( $A D A R 1$ or DSRAD) (2). Disease onset typically occurs during infancy or childhood, and $73 \%$ of patients develop skin lesions $<6$ years of age (3). Case reports of patients presenting with skin lesions at birth are rarely reported; only one case was reported by Hemmati and Lam in 2009 (4). Moreover, there have been limited significant non-cutaneous associations previously reported with DSH. Notably, although there have been numerous reports of associated dystonia, patients with comorbid congenital heart disease (CHD) and DSH have not been reported before.

The present study examined two sporadic cases of DSH, with confirmation of the diagnosis by identification of two novel mutations in the ADARl gene. Notably, one of the affected patients additionally presented with $\mathrm{CHD}$ and succumbed to heart failure at the age of 2 years.

\section{Materials and methods}

Ethical approval. The study protocol was approved by the Shanghai Skin Disease Hospital (Shanghai, China). All patients and 120 ethnically matched control individuals were informed about the purpose of the study and written consent was obtained prior to recruitment and sampling. Informed written consent of minors was obtained from their guardians.

Clinical report. The first patient, an 8-month-old girl, was delivered at 34 weeks by cesarean section due to fetal distress with a birth weight of $1.750 \mathrm{~kg}$. She presented with CHD and hyper- and hypo-pigmented macules on the dorsal aspects of her extremities from birth. On examination at the age of 3 months, an ultrasound revealed a hemangioma and patent foramen ovale. A physical examination revealed a hyperplastic plaque with a healthy skin color (diameter, 2-3 cm) on the central segment of the upper lip (Fig. 1A), and hyper- and hypo-pigmented macules were distributed on the back of her hands (Fig. 1B) and feet (Fig. 1C). Cardiac auscultation revealed a diastolic murmur at the apex, and a diastolic thrill. Levels of creatine kinase isoenzyme-MB were typical; however, the $\mathrm{N}$-terminal pro-brain natriuretic peptide level was $5,140 \mathrm{ng} / \mathrm{ml}$. An echocardiogram disclosed severe mitral 
valve stenosis and regurgitation (Fig. 1D), mild to moderate aortic regurgitation and left atrium and left ventricle dilation. An electrocardiogram revealed sinus tachycardia and a right bundle branch block. A chest computed tomography scan demonstrated an enlarged cardiac shadow and bilateral large pleural effusions. Ultrasonography revealed a small pleural effusion and fluid in the peritoneal cavity. Based on the clinical features and investigation findings, the diagnoses of CHD, DSH and hemangioma were confirmed.

At the age of 6 months, mitral valve surgery was undertaken. An echocardiogram following mitral valve surgery revealed moderate to severe mitral valve stenosis and regurgitation with anterior mitral leaflet prolapse, mild to moderate aortic valve regurgitation and left ventricular and left atrium dilation. At 4 days afterwards, similar results were observed in a second echocardiogram, with the exception of rupture of the chordae tendinae. These findings placed the patient at high risk of acute heart failure, which was the cause of death at age 2 .

The second patient was a 2-year-old Chinese boy, born following a full-term pregnancy by healthy delivery. $\mathrm{He}$ presented with asymptomatic hyper- and hypo-pigmented macules over the dorsum of the hands and feet from birth, and developed freckle-like macules on his face at 1-year-old. Gradually, these lesions progressed. Physical examination revealed that the patient had small freckle-like pigmented macules on his face (Fig. 1E), and hypo- and hyper-pigmented macules on the back of the knees (Fig. 1F) and extremities (Fig. 1G) of irregular shape and size. The rest of the physical examination presented no abnormalities.

ADAR1 mutation analysis. Following informed consent, genomic DNA was extracted from the patients' peripheral blood lymphocytes according to the standard protocol. The present study designed primers flanking all 15 coding exons and intron-exon boundaries of the ADARl gene using the web-based version of the Primer 3.0 program (www.genome .wi.mit.edu/cgi-bin/primer/primer3_www.cgi). A polymerase chain reaction (PCR) was performed in a $15 \mu \mathrm{l}$ reaction volume containing $20 \mathrm{ng}$ genomic DNA, $0.3 \mathrm{mM}$ deoxunucleotides, $0.3 \mu \mathrm{M}$ each primer, $3.0 \mathrm{mM} \mathrm{MgCl}_{2}$ and 0.1 U Taq DNA polymerase (Roche Diagnostics, Basel, Switzerland). The PCR conditions were as follows: Taq activation at $95^{\circ} \mathrm{C}$ for $15 \mathrm{~min}$, followed by 40 cycles of denaturation at $94^{\circ} \mathrm{C}$ for $40 \mathrm{sec}$, annealing at $58^{\circ} \mathrm{C}$ for $60 \mathrm{sec}$ and extension at $72^{\circ} \mathrm{C}$ for $55 \mathrm{sec}$, except that in the first 10 cycles when annealing temperature decreased from 63 to $58^{\circ} \mathrm{C}$ by $0.5^{\circ} \mathrm{C}$ per cycle. The final extension was $72^{\circ} \mathrm{C}$ for $10 \mathrm{~min}$. Following amplification, the products were purified using a QIAquick PCR Purification kit (Qiagen $\mathrm{GmbH}$, Hilden, Germany). ADARl was sequenced using an ABI PRISM $^{\circledR} 3730$ automated sequencer (Applied Biosystems; Thermo Fisher Scientific, Inc., Waltham, MA, USA). Sequence comparisons and analysis were performed using Phred-Phrap-Consed software version 12.0 (http://www. phrap.org/phredphrapconsed.html). In addition, samples from 120 unrelated population-matched controls were sequenced to exclude the possibility that any discovered mutations were polymorphisms in ADARl. Mutations were identified by comparing these results with the reported cDNA reference sequence (GenBank accession no. NM_001111).

\section{Results}

Sequencing analysis of the ADARl gene from the two DSH patients was performed. A nonsense mutation at c.3576 $\mathrm{C}>\mathrm{G}$ (p.Y1192X) in exon 15 of the ADARl gene was identified in Patient 1 (Fig. 2A). The resulting truncated protein was predicted to lack 105 amino acids. A single-base frameshift deletion, c.1912delG, was identified within exon 4 in Patient 2, which generated a pre-terminating codon 15 codons downstream of the deletion site (Fig. 2B). These two mutations, which have not been described in previous studies, were not detected in the 120-unrelated healthy Chinese individuals (Fig. 2C and D), suggesting that they are not common polymorphisms.

\section{Discussion}

DSH is an autosomal-dominant skin disorder, characterized by the presence of hyper- and hypo-pigmented macules primarily on the dorsal aspects of the extremities that appear in infancy or early childhood $(5,6)$. Mutations in the ADARl gene have been identified as the molecular basis of DSH (2). To date, $>120$ mutations, distributed primarily in the deaminase domain of ADARl ( 62.3\%), have been reported (7-9). Although the lesions in DSH are common in infancy and early childhood, and typically stop spreading prior adolescence and then remain unaltered for the rest of life, only one patient with DSH since birth has been reported previously (4). In 2009, Hemmati and Lam (4) first reported a 4-year-old Chinese girl who presented at the authors' pediatric dermatology clinic with reticulate hyper- and hypo-pigmentation of the dorsum of the hands and feet that were present since birth; however, gene analysis was not performed. The two patients examined in the present study developed DSH at birth. Sequencing of the overall coding sequence of $A D A R l$ revealed a nonsense mutation at c.3576C $>\mathrm{G}(\mathrm{p} . \mathrm{Y} 1192 \mathrm{X})$ in Patient 1 and a single-base deletion c.1912delG (p.Glu673ValfsX652) in Patient 2. To the best of the authors' knowledge, these are novel mutations in the $A D A R l$ gene. The present study raises the question of whether these two novel ADARl mutations are associated with the earlier emergence of DSH. Further investigations of $A D A R 1$ mutations are necessary to confirm this possibility.

Although the comorbidity of DSH and other diseases is uncommon, various complications, including dystonia (10-13), acral hypertrophy $(14)$, psoriasis $(15,16)$ and depression (15) have been reported in patients with DSH. However, a patient with DSH complicated by CHD has not previously been reported. The etiology of CHD is complex and is associated with environmental and genetic causes. Studies in human genetics have led to the identification of $>50$ human genes (17) involved in isolated CHD or in genetic syndromes where CHD is part of the phenotype. However, none of these genes were primarily associated with malfunctions of the mitral valve; therefore, the present study did not perform mutation analyses on them. Patient 1 , who had concurrent $\mathrm{CHD}$, succumbed to congestive heart 

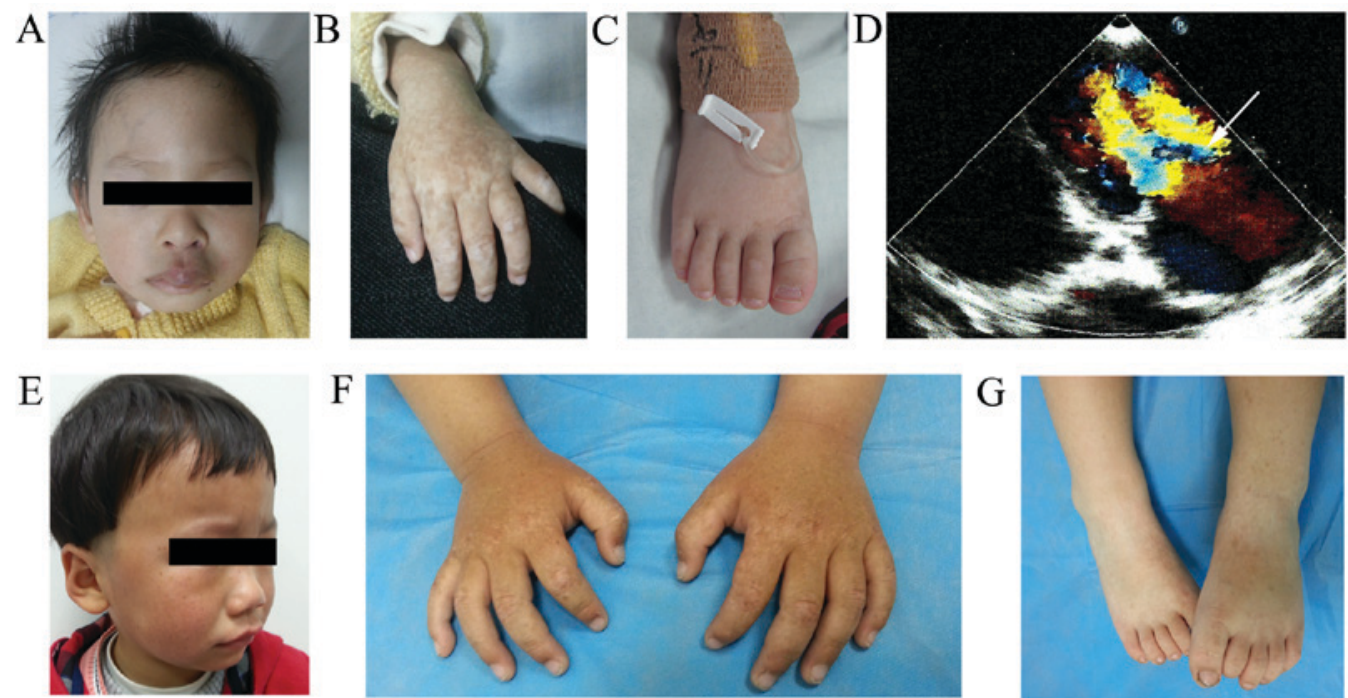

Figure 1. Clinical manifestations of the patients. (A) A hemangioma on the central segment of the upper lip in Patient 1. Hyper- and hypo-pigmented macules on (B) the back of the left hand and (C) the right foot in Patient 1. (D) Doppler echocardiogram with a four-chamber view, demonstrating an image suggestive of severe stenosis and regurgitation (white arrow) of the mitral valve in Patient 1. (E) Freckle-like pigmented macules over the face in Patient 2. Hyper- and hypo-pigmented macules over the (F) hands $(\mathrm{G})$ and feet in Patient 2.

A

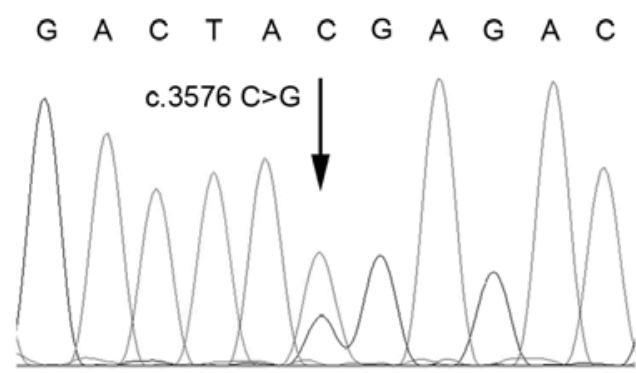

C
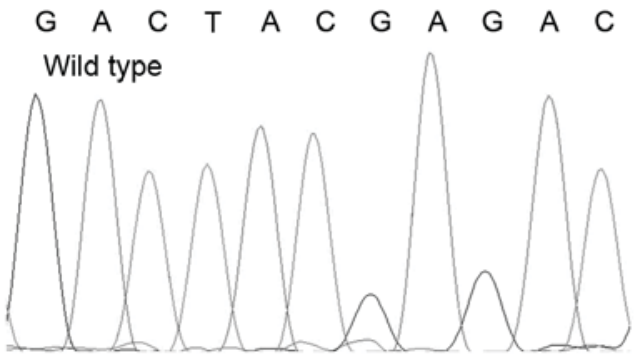

B

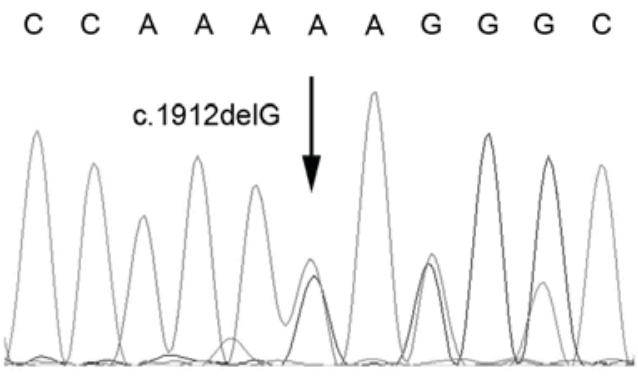

D C $\begin{array}{lllllllllllll} & \text { A } & \text { A } & \text { A } & \text { A } & \text { A } & G & G & G\end{array}$

Wild type

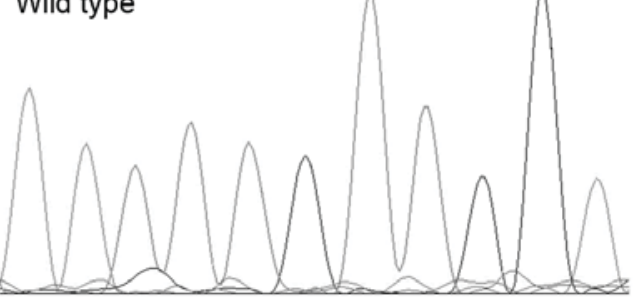

Figure 2. Mutations of the adenosine deaminase acting on RNA1 (ADAR1) gene in the two investigated patients. (A) A nonsense mutation of $\mathrm{c} .3576 \mathrm{C}>\mathrm{G}$ (p.Y1192X) mutation in exon 15 of the ADARl gene in Patient 1. (B) A frameshift mutation of c.1912delG (p.Glu673ValfsX652) in exon 4 of the ADAR1 gene in Patient 2. (C) The sequence of this region of exon 15 of the ADARl gene in healthy subjects. (D) The sequence of the corresponding region of exon 4 of the $A D A R 1$ gene in healthy subjects. Arrowheads indicate the location of the mutations.

failure and was identified as having a p.Y1192X mutation in ADARl. CHD and DSH are hypothesized to be different entities. There is no conclusive evidence that the mutation in ADARl causes CHD. Therefore, the coexistence of these two diseases may be a simple coincidence rather than an intrinsic underlying mechanism.

In conclusion, the present study performed a mutation analysis of the $A D A R l$ gene in two sporadic patients with typical DSH from birth, and identified two novel mutations. To the best of the authors' knowledge, only one case of the existence of DSH since birth has previously been reported. Additionally, the coexistence of DSH and CHD diseases was first reported, and the affected patient succumbed to heart failure. The identification of additional ADARl mutations may facilitate understanding of the association between genotype and phenotype in DSH.

\section{Acknowledgements}

The authors would like to thank all the subjects for their ongoing participation in the present study. The present study was supported by grants from National Natural Science Foundation of China (grant nos. 81201222 and 81272990). 


\section{References}

1. Zhang G, Shao M, Li Z, Gu Y, Du X, Wang X and Li M: Genetic spectrum of dyschromatosis symmetrica hereditaria in Chinese patients including a novel nonstop mutation in ADAR1 gene. BMC Med Genet 17: 14, 2016.

2. Miyamura Y, Suzuki T, Kono M, Inagaki K, Ito S, Suzuki N and Tomita Y: Mutations of the RNA-specific adenosine deaminase gene (DSRAD) are involved in dyschromatosis symmetrica hereditaria. Am J Hum Genet 73: 693-699, 2003.

3. Tomita Y and Suzuki T: Genetics of pigmentary disorders. Am J Med Genet C Semin Med Genet 131C: 75-81, 2004.

4. Hemmati I and Lam J: Hyper-and hypopigmented macules over palms and soles since birth-a case of dyschromatosis symmetrica hereditaria. Dermatol Online J 15: 5, 2009.

5. Toyama I: Dyschromatosis symmetrica hereditaria. Jpn J Dermatol 29: 95-96, 1929.

6. Ostlere LS, Ratnavel RC, Lawlor F, Black MM and Griffiths WA: Reticulate acropigmentation of Dohi. Clin Exp Dermatol 20 477-479, 1995.

7. Li M, Yang L, Li C, Jin C, Lai M, Zhang G, Hu Y, Ji J and Yao Z: Mutational spectrum of the ADAR1 gene in dyschromatosis symmetrica hereditaria. Arch Dermatol Res 302: 469-476, 2010.

8. Stenson PD, Mort M, Ball EV, Howells K, Phillips AD, Thomas NS and Cooper DN: The human gene mutation database: 2008 update. Genome Med 1: 13, 2009.

9. Lai ML, Yang LJ, Zhu XH and Li M: A novel mutation of the DSRAD gene in a Chinese family with dyschromatosis symmetrica hereditaria. Genet Mol Res 11: 1731-1737, 2012.
10. Kondo T, Suzuki T, Ito S, Kono M, Negoro T and Tomita Y: Dyschromatosis symmetrica hereditaria associated with neurological disorders. J Dermatol 35: 662-666, 2008.

11. Tojo K, Sekijima Y, Suzuki T, Suzuki N, Tomita Y, Yoshida K, Hashimoto T and Ikeda S: Dystonia, mental deterioration, and dyschromatosis symmetrica hereditaria in a family with ADAR1 mutation. Mov Disord 21: 1510-1513, 2006.

12. Patrizi A, Manneschi V, Pini A, Baioni E and Ghetti P: Dyschromatosis symmetrica hereditaria associated with idiopathic torsion dystonia. A case report. Acta Derm Venereol 74: 135-137, 1994

13. Kaliyadan F, Vinayan KP, Fernandes B and Jayasree MG: Acral dyschromatosis with developmental regression and dystonia in a seven-year-old child: Dyschromatosis symmetrica hereditaria variant or a new syndrome? Indian J Dermatol Venereol Leprol 75: 412-414, 2009.

14. Murata T, Yagi Y, Tanioka M, Suzuki T, Miyachi Y, Morita K and Utani A: Dyschromatosis symmetrica hereditaria with acral hypertrophy. Eur J Dermatol 21: 649-650, 2011.

15. Luo S, Zheng Y, Ni H, Liu Y, Liu Y, Li X and Liu Q: Novel clinical and molecular findings in Chinese families with dyschromatosis symmetrica hereditaria. J Dermatol 39: 556-558, 2012.

16. Shi BJ, Xue M, Liu Y, Jiang Y and Diao QC: First report of the coexistence of dyschromatosis symmetrica hereditaria and psoriasis: One novel TCT to A mutation in the double-RNA-specific adenosine deaminase gene. J Eur Acad Dermatol Venereol 26: 657-658, 2012.

17. Andersen TA, Troelsen Kde L and Larsen LA: Of mice and men: Molecular genetics of congenital heart disease. Cell Mol Life Sci 71: 1327-1352, 2014 